führt war, obwohl noch $4,82 \mathrm{~g}$. Sulfat unberührt vorhanden waren.

Da wie schon bemerkt, das Bleichlorid sich sehr leicht vom Carbonat trennen liess, also wohl erst recht ohne solches leicht in Lösung mit überging, so erklärt sich, dass die Totalmenge des mit Chlor verbunden gefundenen Bleies, einschliesslich des noch mit $\mathrm{SO}^{3}$ zusammen gebliebenen, nicht dem Quantum Bleisulfat entspricht, welches in Arbeit genommen war. Der Ausfall ist sogar sehr bedeutend, auch wenn man annimmt, dass anch Bleisulfat als solches reichlich in die Waschwässer mit übergegangen, wofür die zu gross ausgefallenen $\mathrm{SO}^{3}$ - Bestimmungen bei obigen 5 Controlen beweisführend auftreten.

Die z. Theil mehr als mangelhaften Hilfsmittel, welche mir zu Gebote stehen, ermöglichen mir leider nicht zu bestimmen, welche Mengen Bleisulfat und Bleichlorid sich neben Alkalisulfaten in Lösung halten können, ohne sich sichtbar umzusetzen, d. h. sich auszuscheiden, so interessant und erwünscht die Versuche auch sein mögen.

Zweifelsohne wirken wie Kochsalz auch Chlorkalium und Chlorammonium und anch das Chlorid des den Alkalimetallen so nahe stehenden Magnesiums in ähnlicher Weise auf Bleisulfat, wenn Bleioxyd gegenwärtig; von letzterem ist dies bereits von mir nachgewiesen, nur ist die Reaction schwächer, die Intensität derselben den angestellten Versuchen nach nur halb so gross als bei Anwendung des ersteren.

\title{
Kleine Mittheilung aus der pharmaceutischen Praxis.
}

\author{
Von C. Schneider in Sprottau.
}

Comprimirte Vegetabilien in Blechbüchsen.

Ein Gespräch bei Gelegenheit der General-Vers, des D. A. V. in Hamburg mit Herrn Dr. Ulex, welcher die Freundlichkeit hatte, mir vieles Interessante über die Verhältnisse der amerikanischen Pharmacie mitzutheilen, war die Veran- 
lassung, den Versuch zu wagen, den Amerikanern Etwas nachzumachen, was mir als ganz besonders rationell einleuchtete, nehmlich: Die Aufbewahrung der Vegetabilien und die Abgabe derselben an das Publikum in gepresstem Zustande. Die Amerikaner pressen ihre vegetabilischen Arzneistoffe in kleine Papier-Päckchen mit einer Art Carton-Umbüllung und geben sie mit Signatur dem Publikum ab. - Ich hielt diese Art der Packung für weniger practisch und theurer als Blechbüchsen (von verzinntem Eisenblech), weil letztere grewaschen und getrocknet unendlich lange zu demselben Zwecke benutzt werden kömnen. Seitdem presse ich Blüthen, Blätter, Kräuter und Wurzeln, frisch gesammelt in eylindrische Blechbüchsen von verschiedener Grösse, (nachdem dieselben zuletzt im Trocken-Oten bis zur Zerreiblichkeit ausgetrocknet) noch warm mit einem Porzellan-Pistill fest, verschliesse die kleinen Büchsen dicht mit Korken, die grösseren mit flachen Blechkappen, und signire dieselben mit den gebräuchlichsten deutschen Namen. - Nach fast dreijähriger Erfahrung kann ich versichern, dass ich mit diesem Verfahren ganz vortreffliche Resultate erzielt und eine Veränderung der Vegetabilien - auch der narkotischen Kräuter - selbst nach mehrjähriger Aufbewahrung nicht wahrgenommen habe, welche den Einflitissen des Witterung'swechsels, und damit den Entwicklungsbedingungen niederer Organismen entzogen, ihro lrische schöne Farbe, Geruch and medicinische Wirksamkeit bewahren. Um mich ganz sicher zu stellen, habe ich vor Linführung der Neuerung den Versuch gemacht, mehrere nur zur If älf te mit Vegetabilien angefülte, mit Kork sorgfältig verschlossene Blechbüchsen einige Wochen lang in einem f'uchten Keller aufzustellen. Am Ende des Versuchs war keine Veränderung an den Vegetabilien wahrzunehmen, und erschienen dieselben völlig frisch und trocken.

Das Publikum hat die Neuerung über alles Erwarten gut aufgenommen, und sich schnell und willig mit der Hinterlegung des Selbstkostenpreises (als Pfand) fiur die Blechbüchse einverstanden erklärt, die Familien haben sich kleine Hausapotheken mit den gebräuchlichsten Thee's eingerichtet, 
W. Stoeder, Alkalö̈bostimmung der Bolivia-Chinarinden etc. 243

und die Hausfrauen finden in dieser Einrichtung ein Analogon ihrer Frucht- und Gemüse-Conserven.

Das Einstopfen der Vegetabilien in die Blechbüchse ist zwar ein wenig mühsam, diese Mühe belohnt sich aber zehnfach in der Ersparniss an Aerger und Zeitverlust wegen Verderbens und Schimmelns, und sogar pecuniär durch die verminderte Ergänzung selbst der narkotischen Vegetabilien.

\section{Alkaloïdbestimmung der Bolivia-Chinarinden auf der internationalen Gartenbauausstellung in Amsterdam.}

Von Professor W. Stoeder in Amsterdam. ${ }^{1}$

Auf der im Jahre 1877 zu Amsterdam abgehaltenen internationalen Gartenbauausstellung bildete die Chinaausstellung einen wichtigen und im hohen Grade interessanten Theil. Neben den Producten der javanischen Chinacultur erschien in dieser Abtheilung von besonderem Werthe eine Sammlung bolivianischer Chinarinden von dem niederländischen Consul E. Schuhkraft herrührend und so vollständig, wie kaum jemals eine derartige Collection gewesen, von der merkwürdigen Monopol - China an, deren Mutterpflanze längst ausgerottet, aber höchst wahrscheinlich noch von Weddell (1846) und Markham (1859) bewundert wurde, bis zu den ganz werthlosen Rinden herab, welche die eingeborenen Chinasammler (Cascarilleros) betrügerischer Weise unter die guten Sorten mengen, unter 27 Nummern in anschaulicher Weise gruppirt. Durch die Bemühungen Schuhkraft's, dessen Verdienst die Jury durch Ertheilung der silbernen Medaille mit Recht ehrte, ist es möglich geworden, zum ersten Male eine Alkaloïdbestimmung in Calisayarinden auszuführen, deren Ursprung von einer bestimmten Kindenspecies festgestellt worden ist, oder deren Abstammung doch mit grösserer Sicherheit bekannt ist und an Ort und Stelle festgestellt

1) Aus Haaxmann's Nieuw Tijdschrift roor do Pharmacie in Nederland mitgetheilt von Th. Husemann. 